\title{
Age and weight at first mating affects plasma leptin concentration but no effects on reproductive performance of gilts
}

\author{
SuHyup Lee ${ }^{1}$, Abdolreza Hosseindoust ${ }^{2}$, YoHan $\mathrm{Choi}^{3}$, MinJu Kim², KwangYeol Kim², JunHyung Lee ${ }^{2}$, \\ YoungHwa Kim ${ }^{3}$ and ByungJo Chae ${ }^{2^{*}}$ \\ ${ }^{1}$ Department of Swine Science, Korea National College of Agriculture and Fisheries, Jeonju 54874, Korea \\ ${ }^{2}$ College of Animal Life Sciences, Kangwon National University, Chuncheon 24341, Korea \\ ${ }^{3}$ Swine Division, National Institute of Animal Science, Rural Development Administration, Cheonan 31000, Korea
}

\begin{abstract}
The objective of this study was to verify the best mating age of gilts at the first parity. Gilts $(n=86)$ were divided into nine groups in a factorial arrangement with three Ages (AG1, $\leq 220 \mathrm{~d} ; A G 2,220$ to $240 \mathrm{~d} ; A G 3,240 \leq \mathrm{d}$ ), and three weights (WT1 $\leq 140 \mathrm{~kg}$; WT2, 140 to $149 \mathrm{~kg}$; WT3, $150 \leq \mathrm{kg}$ ). A higher body weight gain in AG2 sows during gestation. Sows in AG2 group showed a higher body weight gain at first parity and backfat gain in the parity 2 and 3 during gestation. A greater insulin-like growth factor-1 (IGF-1) was observed in AG1 sows compared with AG3 sows at weaning in the second parity. Sows in WT1 group showed a significant positive effect on the plasma IGF-1 at breeding and weaning time in parity 2 . Sows in AG3 group showed a higher plasma leptin at breeding, farrowing, and weaning in the parity 1 , and at farrowing in parity 2 . Sows in WT3 group showed a higher plasma leptin at breeding, farrowing, and weaning in the parities 1 and 2 . Considering the insignificant longevity results, the most efficient time for gilts insemination can be at $220 \mathrm{~d}$ when their body weight is $140 \mathrm{~kg}$ or lower. Keywords: Gilts, Mating, Longevity, Backfat, Litter performance, Leptin
\end{abstract}

\section{Background}

The age and weight at first mating are considered as critical factors for a greater litter size in gilts lifetime production [1,2]. Decades of selection for improved litter size, changes the physiological response of gilts to management or environmental factors [3]. There is a large variation in herd gilts replacement, as almost half the sows are culled every year and their lifetime litter size is only between 30 and 40 piglets [4]. The rate of failure to return to estrus, low litter size, and feet problem are associated with such high rate of cull [2,5]. Removals from the herd up to parity 3 is the minimum economical litters to justify the financial benefit for the farmers [1]. Poor longevity increases the number of required gilts replacement [5-7]. Therefore, even a minor improvement in gilts selection seems essential in order to achieve the highest performance potential.

Age at puberty specify the best mating time in gilts $[4,6]$. The most important management decision to be made by the farmer is to consider the best mating time of gilts to ensure the long-term productivity of sows. In addition, puberty disorder is known as a common problem in replacement gilts [8] and it mostly happens in younger gilts that can physiologically be less mature. This is consistent with previous reports that the selection against early puberty attainment, improve production traits [9].

There have been considerable changes in the breeding manage- 
ment in herds during the past decades. From a modern industry perspective, an ad libitum feeding program is used by many producers in highly prolific developing gilts during the growing period, mostly because of group housing until breeding. In several recent experiments the longevity and performance of gilts have shown to be affected by weight at puberty [7]. Lower body fat content, and higher body weight have been associated with lean growth in the current genotypes [10]. Repeated studies have reported a positive relationship between high body weight at puberty and ovulation rate in gilts [7]. However, a higher body weight has been associated with an increased prematurely culled, mainly due to higher rates of lameness [1,2]. Regarding the genetic background and selection for lean growth, the exact age or weight at puberty is practically unknown. To ensure reproductive performance of the gilts, the traditional managements need to be modified based on accurate mating weight and age, however, it is not easy to define the best age and weight and their effects on longevity. The objective of the present study was to investigate the effect of gilt mating age and weight on the longevity and reproductive factors of sows.

\section{Materials and Methods}

\section{Animals, diets and management}

A total of 86 gilts records during the period 2016 to 2017 from Yorkshire $\times$ Landrace sows were collected. Gilts were divided into nine groups as a factorial arrangement on the basis of three Ages (AG) including AG1 ( $\leq 220 \mathrm{~d}$ ), AG2 (220 to $240 \mathrm{~d}$ ), and AG3 (240 $\leq \mathrm{d})$, and three weights including WT1 ( $\leq 140 \mathrm{~kg})$, WT2 (140 to $149 \mathrm{~kg})$, and WT3 $(150 \leq \mathrm{kg})$ at the first mating time. All the sows were fed a common corn-soybean meal based diet as per NRC [11] requirements for gilts, gestation and lactation. A grain-soybean meal diet fortified similarly to a gestation diet is generally satisfactory for meeting the nutrient needs of the mature boar. During gestation, sows were housed in individual stalls for the 109 days after breeding and then moved to farrowing rooms housed individually in fully slatted farrowing crates after sows were washed and their body weight and backfat recorded. Each crate had a single feeder, and water was always available through a nipple drinker. The farrowing room temperature was maintained at approximately $18^{\circ} \mathrm{C}$ to $20^{\circ} \mathrm{C}$. Rooms were mechanically ventilated. A heat lamp and mat were provided for newborn piglets in each crate. After weaning, sows were returned to their gestation housing systems.

\section{Data collection and measurements}

Sows were weighed and introduced to their lactation diets, beginning from day 109 of gestation and were provided with $2.5 \mathrm{~kg}$ of feed until parturition. Cross-fostering was encouraged within the first 2 days of farrowing. After farrowing, the feed was gradually in- creased through d 5, and then sows were allowed ad libitum intake until weaning (d 24). Sows were fed twice daily at 07:30 and 16:30 $\mathrm{h}$ such that they were allowed ad libitum access to feed and water. The quantity of feed provided per sow was recorded daily from $\mathrm{d}$ 1 to 24 . Feed refusals were weighed and recorded at weaning. No creep feed was provided to suckling piglets. Sow body weight and ultrasonic backfat depth at the P2 position were measured on $\mathrm{d}$ 109 of gestation and at weaning (d 24). Loss of body weight and backfat thickness during lactation was calculated by subtracting the values at weaning from values at $\mathrm{d} 109$ of gestation. Litters were weighed on $\mathrm{d} 1$ and 24 . The parity of the sow and litter size at birth and weaning were evaluated. Total piglets born alive until 5 parities were calculated with consideration of sow retention rate by summing the number piglets produced for all gilts that were initially artificially inseminated [4]. If a sow did not produce a litter in any parity, total born alive of the sow was recorded as 0 for the current parity.

At the first breeding time, day 1 (post farrowing), and day 24 (weaning, after piglet removal) of lactation, 10-mL blood samples were collected after feeding at 15-min intervals for $6 \mathrm{~h}$ from 09:00 to 15:00 for analysis of insulin-like growth factor-1 (IGF-1) and leptin by kits (Endocrine Technologies Inc., USA) were used and their concentrations were determined in duplicate by ELISA using the Biolog MicroStation system.

Approximately $25 \mathrm{~mL}$ of colostrum and milk samples were manually collected from each sow on days 1 and 10 postpartum respectively to evaluate their composition. Sows were given $1 \mathrm{~mL}$ of oxytocin $(1 \mathrm{U} / \mathrm{mL})$ to stimulate milk release. Milk was manually collected from all functional teats after alcohol swabbing. Milk samples were immediately frozen at $-20^{\circ} \mathrm{C}$ and analyzed using an infrared milk analyzer (Milko Scan 133B. Analyser; Foss Electric, Hillerod, Denmark).

\section{Statistical analysis}

Data generated in the present experiment was analyzed as a $3 \times$ 3 factorial arrangement in a completely randomized design. Data were replicated over time, whereas the age and weight at first mating were the fixed effect. Sow was considered the experimental unit. The main effects of parameters, and their interactions were determined by mixed procedure of SAS statistical program (SAS Inst., Inc., Cary, NC, USA). A p-values $\leq 0.05$ were considered statistically significant. The data were tested for main effects of age, weight at first mating, and their possible interaction. The following model statement was used:

$$
\mathrm{Y}_{\mathrm{ijt}}=\mu+\alpha_{\mathrm{i}}+\beta_{\mathrm{j}}+\gamma_{\mathrm{t}}+\alpha \beta_{\mathrm{ij}}+\varepsilon_{\mathrm{ijt}}
$$

where $Y_{\mathrm{ijt}}=$ measured response, $\mu=$ overall mean, $\alpha_{\mathrm{i}}=$ age effect, $\beta_{\mathrm{j}}$ 
= weight effect, $\gamma_{t}=$ the fixed time effect when the measurement was taken, $\alpha \beta_{\mathrm{ij}}=$ interaction between housing and back fat effect, and $\varepsilon_{\mathrm{ijt}}=$ residual error.

\section{Results}

\section{Body weight and longevity}

The first parity average body weight of AG1, AG2, and AG3 groups at insemination were $145.7,147.8$, and $151.2 \mathrm{~kg}$ respectively (Table 1). No difference in body weight was observed between sows in AG groups at mating time, however, sows in AG3 group tended $(p=0.09)$ to have increased body weight compared with AG1 during parity 1 and 2. Sows in WT3 group showed significantly the highest $(p<0.05)$ body weight at mating during parities 1,2 , and 4 . There was a tendency $(p=0.08)$ for a higher body weight in WT3 sows compared with WT1 sows during parity 3. At d 109 of gestation, the only body weight difference among AG groups was observed at the first party, where sows in AG3 and AG1 groups showed the highest $(p<0.01)$ and lowest $(p<0.01)$ body weight, respectively. There were no differences in body weight between the groups for the second, third, forth, and fifth parities. At d 109 of gestation, sows in WT3 group had the highest body weight $(p<0.05)$ at the parities 1,2 , and 3, but there was no difference among the groups in the fifth parity. At weaning time, sows in AG3 group had the highest $(p<0.05)$ body weight at the first parity, however, no difference was observed among the groups in the second, third, fourth, and fifth parities. At weaning time, a higher body weight was observed in sows in WT3 group in the first, second and third parities, but there was no difference $(p<$ 0.01) in body weight between the groups in the second, and third parities. There was no association between the age and weight of sows at mating and longevity.

\section{Backfat thickness}

The backfat thickness at insemination, gestation, and weaning are shown in Table 2. At insemination time, the backfat thickness was tended $(p=0.09)$ to be higher in sows in AG3 group compared with AG1 sows in the first, and second parities, and was not influenced between sows in AG groups in parities 3, 4, and 5. At insemination time, the backfat thickness was higher $(p<0.05)$ in WT3 sows compared with WT1 and WT2 sows in the first and second parities $(p<0.05)$, but no difference was observed between WT sows in the third, forth, and fifth parities. At d 109 of gestation, there was no difference between the sows in AG groups,

Table 1. Effects of age (AG) and weight (WT) of gilts at first mating on mating weight, gestation weight, weaning weight, and longevity over five consecutive parities

\begin{tabular}{|c|c|c|c|c|c|c|c|c|c|c|}
\hline & \multicolumn{3}{|c|}{ AG (days) } & \multicolumn{3}{|c|}{ WT (kg) } & \multirow{2}{*}{ SEM } & \multicolumn{3}{|c|}{$p$-value } \\
\hline & $<220$ & $220-240$ & $241 \leq$ & $<140$ & $140-149$ & $150 \leq$ & & AG & WT & $A G \times W T$ \\
\hline Mating age & 217.3 & 235.0 & 246.5 & 219.5 & 233.1 & 240.0 & & & & \\
\hline \multicolumn{11}{|c|}{ Body weight at mating $(\mathrm{kg})$} \\
\hline Parity 1 & 145.7 & 147.8 & 151.2 & $134.3^{\mathrm{c}}$ & $145.1^{\mathrm{b}}$ & $155.0^{\mathrm{a}}$ & 2.26 & 0.071 & $<0.01$ & 0.354 \\
\hline Parity 2 & 164.8 & 170.9 & 172.0 & $161.9^{c}$ & $168.4^{b}$ & $175.7^{\mathrm{a}}$ & 3.56 & 0.087 & $<0.01$ & 0.619 \\
\hline Parity 3 & 182.9 & 186.2 & 187.0 & 180.0 & 183.7 & 191.6 & 5.11 & 0.660 & 0.080 & 0.525 \\
\hline Parity 4 & 197.4 & 201.4 & 200.9 & $193.5^{b}$ & $198.6^{b}$ & $206.3^{\mathrm{a}}$ & 4.12 & 0.646 & 0.042 & 0.199 \\
\hline Parity 5 & 217.8 & 220.2 & 217.2 & 211.6 & 219.9 & 220.8 & 4.29 & 0.694 & 0.127 & 0.381 \\
\hline \multicolumn{11}{|c|}{ Body weight at d 109 of gestation $(\mathrm{kg})$} \\
\hline Parity 1 & $182.9^{b}$ & $191.1^{\mathrm{a}}$ & $193.6^{\mathrm{a}}$ & $180.1^{\mathrm{c}}$ & $189.1^{\mathrm{b}}$ & $195.6^{\mathrm{a}}$ & 2.27 & $<0.01$ & $<0.01$ & 0.549 \\
\hline Parity 2 & 198.2 & 203.7 & 204.8 & $194.7^{c}$ & $200.9^{b}$ & $209.7^{\mathrm{a}}$ & 3.45 & 0.112 & $<0.01$ & 0.737 \\
\hline Parity 3 & 211.7 & 215.8 & 214.1 & $206.1^{\mathrm{c}}$ & $212.6^{\mathrm{b}}$ & $220.9^{\mathrm{a}}$ & 3.38 & 0.530 & $<0.01$ & 0.398 \\
\hline Parity 4 & 226.6 & 231.8 & 229.1 & 221.6 & 228.8 & 234.9 & 6.69 & 0.813 & 0.055 & 0.280 \\
\hline Parity 5 & 247.3 & 250.0 & 245.1 & 240.4 & 248.3 & 250.9 & 7.26 & 0.441 & 0.193 & 0.544 \\
\hline \multicolumn{11}{|c|}{ Body weight at weaning (kg) } \\
\hline Parity 1 & $165.0^{\mathrm{b}}$ & $171.2^{\mathrm{a}}$ & $171.8^{\mathrm{a}}$ & $162.4^{c}$ & $168.4^{b}$ & $175.2^{\mathrm{a}}$ & 2.01 & 0.036 & $<0.01$ & 0.480 \\
\hline Parity 2 & 182.3 & 185.4 & 186.7 & $178.9^{c}$ & $183.6^{\mathrm{b}}$ & $190.9^{a}$ & 3.09 & 0.349 & 0.033 & 0.622 \\
\hline Parity 3 & 197.9 & 201.3 & 198.6 & $191.4^{c}$ & $198.2^{b}$ & $206.1^{a}$ & 3.82 & 0.678 & $<0.01$ & 0.356 \\
\hline Parity 4 & 217.1 & 221.5 & 219.2 & 212.5 & 219.1 & 224.2 & 7.14 & 0.792 & 0.113 & 0.399 \\
\hline Parity 5 & 237.3 & 240.1 & 233.9 & 230.6 & 237.6 & 240.6 & 4.88 & 0.667 & 0.271 & 0.645 \\
\hline Longevity & 3.92 & 4.09 & 4.04 & 3.97 & 4.12 & 3.90 & 0.20 & 0.508 & 0.371 & 0.856 \\
\hline
\end{tabular}

Means $\left({ }^{a-c}\right)$ in column are significantly different $(p<0.01)$. 
Table 2. Effects of age (AG) and weight (WT) of gilts at first mating on backfat thickness (BFT) over five consecutive parities

\begin{tabular}{|c|c|c|c|c|c|c|c|c|c|c|}
\hline & \multicolumn{3}{|c|}{ AG (days) } & \multicolumn{3}{|c|}{ WT (kg) } & \multirow{2}{*}{ SEM } & \multicolumn{3}{|c|}{$p$-value } \\
\hline & $<220$ & $220-240$ & $241 \leq$ & $<140$ & $140-149$ & $150 \leq$ & & AG & WT & $A G \times W T$ \\
\hline \multicolumn{11}{|c|}{ BFT at insemination (mm) } \\
\hline Parity 1 & 15.1 & 15.6 & 16.1 & 14.8 & 15.1 & 16.1 & 0.39 & 0.079 & 0.011 & 0.194 \\
\hline Parity 2 & 15.5 & 15.8 & 16.4 & 15.2 & 15.2 & 16.4 & 0.41 & 0.086 & 0.043 & 0.756 \\
\hline Parity 3 & 15.8 & 16.1 & 16.4 & 15.6 & 15.8 & 16.4 & 0.51 & 0.192 & 0.162 & 0.654 \\
\hline Parity 4 & 16.4 & 17.1 & 17.2 & 16.3 & 17.0 & 17.1 & 0.43 & 0.158 & 0.149 & 0.865 \\
\hline Parity 5 & 17.8 & 18.4 & 17.5 & 17.4 & 18.2 & 17.8 & 0.69 & 0.310 & 0.382 & 0.282 \\
\hline \multicolumn{11}{|c|}{ BFT at day 109 of gestation $(\mathrm{mm})$} \\
\hline Parity 1 & 17.6 & 19.0 & 19.1 & $17.5^{\mathrm{b}}$ & $17.9^{\mathrm{ab}}$ & $19.4^{\mathrm{a}}$ & 0.58 & 0.088 & 0.027 & 0.541 \\
\hline Parity 2 & 17.4 & 18.4 & 18.8 & 17.4 & 18.0 & 19.0 & 1.26 & 0.438 & 0.400 & 0.670 \\
\hline Parity 3 & 18.0 & 19.0 & 18.9 & 18.1 & 18.7 & 19.0 & 0.68 & 0.433 & 0.555 & 0.673 \\
\hline Parity 4 & 19.1 & 20.0 & 19.6 & 18.8 & 19.8 & 19.8 & 1.06 & 0.723 & 0.625 & 0.560 \\
\hline Parity 5 & 20.0 & 20.7 & 21.2 & 19.7 & 20.4 & 22.8 & 1.89 & 0.922 & 0.364 & 0.759 \\
\hline \multicolumn{11}{|c|}{ BFT at weaning $(\mathrm{mm})$} \\
\hline Parity 1 & 15.9 & 16.4 & 16.4 & 15.5 & 15.7 & 16.6 & 0.38 & 0.230 & 0.023 & 0.676 \\
\hline Parity 2 & 16.0 & 16.0 & 16.5 & 15.6 & 15.5 & 16.5 & 0.38 & 0.254 & 0.071 & 0.946 \\
\hline Parity 3 & 16.3 & 16.8 & 17.0 & 16.3 & 16.8 & 16.7 & 0.67 & 0.644 & 0.785 & 0.924 \\
\hline Parity 4 & 17.6 & 18.3 & 18.0 & 17.4 & 18.1 & 18.2 & 0.76 & 0.889 & 0.508 & 0.728 \\
\hline Parity 5 & 18.4 & 19.0 & 18.4 & 17.7 & 18.8 & 18.9 & 0.93 & 0.652 & 0.287 & 0.661 \\
\hline
\end{tabular}

Means $\left({ }^{(, .,}\right)$in column are significantly different $(p<0.01)$.

however, there was a tendency to a slightly higher $(p=0.09)$ backfat thickness in sows in AG3 group at first parity. At d 109 of gestation, the result of the first parity showed a higher $(p<0.05)$ backfat thickness in sows in WT3 group compared with WT1 and there was no difference between WT groups in the rest of parities. At weaning time, there was no difference in sows' backfat thickness between AG groups. At weaning time, the backfat thickness was higher $(p<0.05)$ in WT3 group compared with WT2 and WT1 groups in the first parity. No significant difference was observed between the WT sows in the rest of parities, however, there was a tendency $(p=0.09)$ towards increased backfat thickness in sows in WT3 group in the second parity.

\section{Body weight and backfat thickness change}

The effects of the first mating time on sow body weight and backfat change are presented in Table 3 . The result of the first parity showed a higher $(p<0.05)$ body weight gain in AG2 sows compared with AG1 during gestation. There was a tendency $(p=$ 0.07 ) to a higher body weight gain in WT1 sows at first parity and WT3 at third parity. There was no difference in body weight loss in either AG or WT sows, and only a tendency $(p=0.07)$ for higher body weight loss was observed in AG3 sows compared with AG1. Sows in AG2 group showed a significant $(p<0.05)$ positive effect on the backfat gain during gestation compared with AG1 sows in the parity 2 and 3 , but only a tendency $(p=0.06)$ was observed in backfat gain in the first parity. There was a tendency $(p=0.09)$ to a lower backfat gain for WT1 sows during gestation in parities 1 and 2. A lower $(p<0.01)$ backfat loss was observed in AG1 sows in the first party during lactation. There were increases $(p<0.05)$ or tendencies $(p=0.08)$ toward backfat loss during lactation in WT3 sows in the first and second parity respectively.

\section{Feed intake and litter performance}

The present study showed that the age and weight of gilts at first mating did not influence the feed intake (Table 4), however, there were tendencies $(p=0.07)$ toward a higher feed intake during lactation in AG1 and WT1 sows in the first parity. There were no differences in litter size and the number of weaned piglets among the groups throughout the five consecutive parities.

\section{Blood parameters}

The effects of the first mating time on blood parameters are presented in Table 5. The result of the breeding time showed a tendency $(p=0.08)$ for higher IGF-1 in AG1 sows. A greater IGF-1 was shown in AG1 sows compared with AG3 sows at weaning in the second parity, but no difference was observed in concentration of plasma IGF-1 at farrowing and weaning in the first and third parities. Sows in WT1 group showed a significantly positive effect $(p<$ $0.05)$ on the plasma IGF-1 at breeding time and weaning time in parity 2 compared with WT2 and WT2. There was no variation in 
Table 3. Effects of age (AG) and weight (WT) of gilts at first mating on body weight and backfat thickness change during gestation and lactation over five consecutive parities

\begin{tabular}{|c|c|c|c|c|c|c|c|c|c|c|}
\hline & \multicolumn{3}{|c|}{ AG (days) } & \multicolumn{3}{|c|}{ WT (kg) } & \multirow{2}{*}{ SEM } & \multicolumn{3}{|c|}{$p$-value } \\
\hline & $<220$ & 220-240 & $241 \leq$ & $<140$ & $140-149$ & $150 \leq$ & & AG & WT & $A G \times W T$ \\
\hline \multicolumn{11}{|c|}{ Body weight gain during gestation (kg) } \\
\hline Parity 1 & $37.2^{\mathrm{b}}$ & $43.3^{\mathrm{a}}$ & $42.5^{\mathrm{ab}}$ & 45.8 & 44.0 & 40.6 & 2.17 & 0.046 & 0.069 & 0.216 \\
\hline Parity 2 & 33.4 & 32.9 & 32.8 & 32.7 & 32.4 & 34.0 & 2.00 & 0.999 & 0.869 & 0.900 \\
\hline Parity 3 & 28.8 & 29.6 & 27.1 & 26.1 & 28.9 & 29.3 & 1.62 & 0.133 & 0.095 & 0.545 \\
\hline Parity 4 & 29.2 & 30.4 & 28.2 & 28.1 & 30.2 & 28.6 & 1.68 & 0.358 & 0.482 & 0.862 \\
\hline Parity 5 & 29.6 & 29.7 & 27.9 & 28.7 & 28.4 & 30.1 & 1.70 & 0.858 & 0.424 & 0.649 \\
\hline \multicolumn{11}{|c|}{ Body weight loss during lactation (kg) } \\
\hline Parity 1 & 17.9 & 19.9 & 21.8 & 17.7 & 20.7 & 20.4 & 1.69 & 0.071 & 0.104 & 0.974 \\
\hline Parity 2 & 15.9 & 18.3 & 18.1 & 15.8 & 17.3 & 18.8 & 1.74 & 0.378 & 0.133 & 0.804 \\
\hline Parity 3 & 13.8 & 14.6 & 15.5 & 14.7 & 14.4 & 14.8 & 2.59 & 0.921 & 0.968 & 0.700 \\
\hline Parity 4 & 9.5 & 10.2 & 9.9 & 9.1 & 9.7 & 10.7 & 1.34 & 0.916 & 0.480 & 0.880 \\
\hline Parity 5 & 10.1 & 9.8 & 11.2 & 9.8 & 10.7 & 10.4 & 1.78 & 0.528 & 0.907 & 0.760 \\
\hline \multicolumn{11}{|c|}{ Backfat gain during gestation (mm) } \\
\hline Parity 1 & 2.51 & 3.39 & 2.99 & 2.63 & 2.81 & 3.32 & 0.32 & 0.059 & 0.091 & 0.965 \\
\hline Parity 2 & $1.90^{\mathrm{b}}$ & $2.61^{\mathrm{a}}$ & $2.39^{\mathrm{ab}}$ & $2.23^{\mathrm{b}}$ & 2.79 & 2.58 & 0.24 & 0.049 & 0.081 & 0.563 \\
\hline Parity 3 & $2.20^{\mathrm{b}}$ & $2.91^{\mathrm{a}}$ & $2.53^{\mathrm{ab}}$ & 2.43 & 2.89 & 2.63 & 0.25 & 0.047 & 0.109 & 0.101 \\
\hline Parity 4 & 2.70 & 2.92 & 2.40 & 2.56 & 2.71 & 2.66 & 0.28 & 0.568 & 0.851 & 0.103 \\
\hline Parity 5 & 2.28 & 2.29 & 3.74 & 2.28 & 2.24 & 4.98 & 1.96 & 0.819 & 0.232 & 0.895 \\
\hline \multicolumn{11}{|c|}{ Backfat loss during lactation (mm) } \\
\hline Parity 1 & $1.71^{\mathrm{b}}$ & $2.60^{\mathrm{a}}$ & $2.71^{\mathrm{a}}$ & $1.97^{\mathrm{b}}$ & $2.23^{\mathrm{ab}}$ & $2.82^{\mathrm{a}}$ & 0.26 & $<0.01$ & 0.021 & 0.703 \\
\hline Parity 2 & 1.42 & 2.40 & 2.33 & 1.81 & 2.48 & 2.44 & 0.29 & 0.102 & 0.083 & 0.792 \\
\hline Parity 3 & 1.73 & 2.19 & 1.97 & 1.78 & 1.83 & 2.25 & 0.65 & 0.670 & 0.793 & 0.952 \\
\hline Parity 4 & 1.47 & 1.77 & 1.60 & 1.46 & 1.66 & 1.64 & 0.111 & 0.849 & 0.872 & 0.941 \\
\hline Parity 5 & 1.67 & 1.71 & 2.84 & 2.03 & 1.63 & 3.84 & 1.96 & 0.885 & 0.402 & 0.785 \\
\hline
\end{tabular}

Means $\left({ }^{(a, b}\right)$ in column are significantly different $(p<0.01)$.

plasma concentration of IGF-1 between WT groups in parities 1 and 3. Sows in AG3 group showed a significant $(p<0.05)$ positive effect on the plasma leptin compared with AG1 sows at breeding, farrowing, and weaning in the parity 1 , and at farrowing in parity 2 , but only a tendency $(p=0.08)$ was observed at weaning time in the second parity. Sows in WT3 group showed a higher $(p<0.01)$ plasma leptin compared with WT1 and WT2 sows at breeding, farrowing, and weaning in the parities 1 and 2, but only a tendency $(p=0.09)$ was observed at weaning time in the third parity.

\section{Milk composition}

The effects of mating age on colostrum and milk yield in the first parity are presented in Table 6 . The first parity colostrum analysis showed that sows in AG1 group had significantly higher $(p<0.05)$ protein and lactose contents compared with AG3. Sows in AG3 and AG2 groups showed the highest $(p<0.05)$ fat and lactose in milk, respectively. There was no difference in colostrum and milk protein among the WT groups. Colostrum and milk fat contents were greater $(p<0.05)$ in WT3 sows compared with WT1, and there was a tendency $(p=0.05)$ for higher colostrum lactose in WT1 sows compared with WT3 sows in the first parity. There was no significant difference between the age and weight at first mating and protein, fat, and lactose of milk or colostrum in the second and third parities (data not shown).

\section{Discussion}

Many gilt development programs recommend that gilts are first bred at a minimum of 210 days of age [12]. However, recent protocols from Europe, in particular Denmark, now recommend that gilts are bred at an older age and heavier weight [13]. It is generally accepted that, age at first exposure to a mature boar seems to be the best predictor of gilt response to puberty $[7,8]$. The longevity and reproductive performance of current study were not affected by mating age of gilts, therefore mating in lower age $(140 \mathrm{~d})$ can be appropriate to achieve the highest performance. Inconsistent to this study, a previous study has shown that gilts are suitable to be inseminated at $135 \mathrm{~kg}$ body weight regardless of the backfat thick- 
Table 4. Effects of age (AG) and weight (WT) of gilts at first mating on daily feed intake and litter performance during lactation over five consecutive parities

\begin{tabular}{|c|c|c|c|c|c|c|c|c|c|c|}
\hline & \multicolumn{3}{|c|}{ AG (days) } & \multicolumn{3}{|c|}{ WT (kg) } & \multirow{2}{*}{ SEM } & \multicolumn{3}{|c|}{$p$-value } \\
\hline & $<220$ & $220-240$ & $241 \leq$ & $<140$ & $140-149$ & $150 \leq$ & & AG & WT & $A G \times W T$ \\
\hline \multicolumn{11}{|c|}{ Daily feed intake during lactation $(\mathrm{kg} / \mathrm{d})$} \\
\hline Parity 1 & 5.38 & 4.95 & 4.76 & 5.39 & 4.96 & 4.87 & 0.24 & 0.069 & 0.093 & 0.438 \\
\hline Parity 2 & 6.11 & 5.98 & 5.93 & 6.20 & 5.97 & 5.91 & 0.28 & 0.744 & 0.534 & 0.790 \\
\hline Parity 3 & 6.71 & 6.66 & 6.86 & 6.74 & 6.87 & 6.58 & 0.58 & 0.841 & 0.922 & 0.783 \\
\hline Parity 4 & 7.29 & 6.86 & 6.66 & 7.10 & 6.98 & 6.75 & 0.59 & 0.524 & 0.945 & 0.785 \\
\hline Parity 5 & 6.90 & 6.90 & 6.42 & 6.76 & 6.67 & 6.80 & 0.40 & 0.303 & 0.970 & 0.747 \\
\hline \multicolumn{11}{|l|}{ Litter size } \\
\hline Parity 1 & 11.6 & 11.6 & 11.6 & 11.3 & 11.6 & 11.7 & 0.23 & 0.903 & 0.451 & 0.678 \\
\hline Parity 2 & 11.8 & 11.2 & 11.6 & 11.8 & 11.6 & 11.3 & 0.31 & 0.642 & 0.956 & 0.739 \\
\hline Parity 3 & 12.2 & 12.3 & 11.7 & 12.5 & 11.9 & 12.0 & 0.35 & 0.932 & 0.231 & 0.311 \\
\hline Parity 4 & 11.4 & 12.0 & 11.9 & 11.9 & 11.4 & 12.0 & 0.43 & 0.160 & 0.344 & 0.736 \\
\hline Parity 5 & 11.3 & 11.7 & 11.2 & 11.7 & 10.9 & 11.8 & 0.35 & 0.290 & 0.269 & 0.212 \\
\hline \multicolumn{11}{|c|}{ Weaned piglets } \\
\hline Parity 1 & 9.7 & 9.7 & 9.8 & 9.6 & 9.9 & 9.7 & 0.18 & 0.891 & 0.740 & 0.864 \\
\hline Parity 2 & 9.9 & 10.1 & 10.2 & 10.0 & 10.1 & 10.1 & 0.23 & 0.216 & 0.494 & 0.293 \\
\hline Parity 3 & 10.4 & 10.6 & 10.2 & 10.3 & 10.7 & 10.1 & 0.21 & 0.318 & 0.223 & 0.293 \\
\hline Parity 4 & 10.4 & 10.4 & 10.4 & 10.5 & 10.4 & 10.3 & 0.21 & 0.701 & 0.300 & 0.192 \\
\hline Parity 5 & 10.2 & 9.9 & 10.1 & 10.1 & 10.0 & 10.2 & 0.24 & 0.564 & 0.334 & 0.355 \\
\hline
\end{tabular}

Table 5. Effects of age (AG) and weight (WT) of gilts at first mating on blood metabolites of sows over three consecutive parities

\begin{tabular}{|c|c|c|c|c|c|c|c|c|c|c|c|}
\hline & & \multicolumn{3}{|c|}{ AG (days) } & \multicolumn{3}{|c|}{ WT (kg) } & \multirow{2}{*}{ SEM } & \multicolumn{3}{|c|}{$p$-value } \\
\hline & & $<220$ & $220-240$ & $241 \leq$ & $<140$ & $140-149$ & $150 \leq$ & & AG & WT & $A G \times W T$ \\
\hline \multicolumn{12}{|c|}{ Plasma IGF-1 (ng/mL) } \\
\hline Breeding & & 171.8 & 165.1 & 162.9 & $175.6^{\mathrm{a}}$ & $165.9^{b}$ & $158.3^{b}$ & 3.7 & 0.077 & 0.011 & 0.236 \\
\hline \multirow[t]{2}{*}{ Parity 1} & Farrowing & 158.7 & 153.2 & 154 & 155.9 & 156.4 & 153.6 & 2.67 & 0.344 & 0.625 & 0.347 \\
\hline & Weaning & 161.9 & 156.3 & 157.7 & 159.4 & 158.6 & 157.9 & 1.96 & 0.181 & 0.822 & 0.522 \\
\hline \multirow[t]{2}{*}{ Parity 2} & Farrowing & 154.6 & 151.3 & 150.2 & 153.6 & 151.1 & 151.4 & 1.92 & 0.317 & 0.612 & 0.311 \\
\hline & Weaning & $159.9^{\mathrm{a}}$ & $155.1^{\mathrm{ab}}$ & $153.3^{b}$ & $161.2^{\mathrm{a}}$ & $153.6^{b}$ & $153.5^{\mathrm{b}}$ & 1.54 & 0.034 & $<0.01$ & 0.289 \\
\hline \multirow[t]{2}{*}{ Parity 3} & Farrowing & 144.7 & 142.1 & 140.7 & 142.9 & 142.6 & 142 & 2.34 & 0.526 & 0.796 & 0.451 \\
\hline & Weaning & 147.9 & 146.8 & 147.1 & 146.8 & 148.1 & 146.9 & 2.13 & 0.944 & 0.866 & 0.417 \\
\hline \multicolumn{12}{|c|}{ Plasma leptin (ng/mL) } \\
\hline \multicolumn{2}{|c|}{ Breeding } & $2.93^{b}$ & $3.17^{\mathrm{ab}}$ & $3.29^{\mathrm{a}}$ & $2.81^{\mathrm{c}}$ & $3.12^{\mathrm{b}}$ & $3.46^{\mathrm{a}}$ & 0.07 & 0.014 & $<0.01$ & 0.111 \\
\hline \multirow[t]{2}{*}{ Parity 1} & Farrowing & $2.74^{\mathrm{b}}$ & $2.91^{\mathrm{ab}}$ & $2.99^{\mathrm{a}}$ & $2.61^{\mathrm{c}}$ & $2.89^{\mathrm{b}}$ & $3.14^{\mathrm{a}}$ & 0.05 & 0.010 & $<0.01$ & 0.185 \\
\hline & Weaning & $2.63^{\mathrm{b}}$ & $2.72^{\mathrm{ab}}$ & $2.87^{\mathrm{a}}$ & $2.56^{\mathrm{b}}$ & $2.67^{b}$ & $2.99^{\mathrm{a}}$ & 0.05 & 0.025 & $<0.01$ & 0.298 \\
\hline \multirow[t]{2}{*}{ Parity 2} & Farrowing & $2.85^{\mathrm{b}}$ & $2.92^{\mathrm{ab}}$ & $3.07^{\mathrm{a}}$ & $2.72^{\mathrm{b}}$ & $2.81^{\mathrm{b}}$ & $3.31^{\mathrm{a}}$ & 0.05 & 0.026 & $<0.01$ & 0.328 \\
\hline & Weaning & 2.73 & 2.82 & 2.91 & $2.64^{\mathrm{b}}$ & $2.91^{\mathrm{a}}$ & $2.91^{\mathrm{a}}$ & 0.05 & 0.083 & 0.01 & 0.587 \\
\hline \multirow[t]{2}{*}{ Parity 3} & Farrowing & 2.71 & 2.73 & 2.78 & 2.72 & 2.75 & 2.75 & 0.03 & 0.396 & 0.622 & 0.622 \\
\hline & Weaning & 2.75 & 2.82 & 2.85 & 2.73 & 2.81 & 2.88 & 0.04 & 0.112 & 0.089 & 0.349 \\
\hline
\end{tabular}

Means $\left(^{(--c}\right)$ in column are significantly different $(p<0.01)$.

IGF, insulin-like growth factor.

ness or age without any negative effects on litter performance over three parities [14]. In contrast, it has been proposed that a longer lifetime productivity is considered in gilts mated at a younger age, nevertheless they have a smaller litter size in the first parity [8]. Furthermore, the result of this study showed that weight at mating also did not affect the longevity and litter performance. It has been 
Table 6. Effects of age (AG) and weight (WT) of gilts at first mating on milk and colostrum compositions of sows in the first parity

\begin{tabular}{|c|c|c|c|c|c|c|c|c|c|c|}
\hline & \multicolumn{3}{|c|}{ AG (days) } & \multicolumn{3}{|c|}{ WT (kg) } & \multirow{2}{*}{ SEM } & \multicolumn{3}{|c|}{$p$-value } \\
\hline & $<220$ & $220-240$ & $241 \leq$ & $<140$ & $140-149$ & $150 \leq$ & & AG & WT & $A G \times W T$ \\
\hline \multicolumn{11}{|c|}{ Colostrum (g/L) } \\
\hline Protein & $57.1^{\mathrm{a}}$ & $55.2^{\mathrm{ab}}$ & $50.3^{b}$ & 55.2 & 52.6 & 54.8 & 1.55 & 0.048 & 0.349 & 0.316 \\
\hline Fat & 48.9 & 49.5 & 52.2 & $47.1^{\mathrm{b}}$ & $50.2^{\mathrm{ab}}$ & $53.3^{\mathrm{a}}$ & 1.31 & 0.208 & 0.011 & 0.159 \\
\hline Lactose & $54.5^{\mathrm{a}}$ & $54.3^{\mathrm{a}}$ & $49.6^{b}$ & 53.6 & 53.2 & 51.6 & 1.18 & 0.02 & 0.053 & 0.327 \\
\hline \multicolumn{11}{|l|}{ Milk (g/L) } \\
\hline Protein & 53.4 & 53 & 48.8 & 51.3 & 51.6 & 52.3 & 1.97 & 0.256 & 0.824 & 0.567 \\
\hline Fat & $46.2^{b}$ & $47.3^{\mathrm{b}}$ & $52.5^{\mathrm{a}}$ & $45.3^{b}$ & $48.1^{\mathrm{ab}}$ & $52.6^{\mathrm{a}}$ & 1.26 & 0.012 & $<0.01$ & 0.265 \\
\hline Lactose & $53.7^{\mathrm{ab}}$ & $54.4^{\mathrm{a}}$ & $50.6^{b}$ & 54.3 & 52.9 & 51.5 & 0.96 & 0.042 & 0.135 & 0.415 \\
\hline
\end{tabular}

Means $\left({ }^{-a-c}\right)$ in column are significantly different $(p<0.01)$.

stated that growth rate and body weight of gilts are more correlated to litter size in the first parity than the total farrowing rate [12]. A higher production cost is expected for gilts mated older and heavier due to higher body weight and likely higher maintenance requirements during their lifetime [4]. The insignificant results in this study may be due to choosing a short range for age and weight at insemination. The gilts inseminated $<220$ days of age at lower than $140 \mathrm{~kg}$ body weight showed no reproductive performance compared with older and heavier gilts, with an expectation of lower maintenance costs. Therefore, considering the cost of maintenance, the younger age and lighter weight would be the most efficient mating condition for gilts.

Apart from age and body weight, backfat thickness is one of the most important parameters for selecting female pigs in breeding herds due to its role in reproductive performances. Backfat thickness in pigs is commonly used as a predictor of fat quantity and lean content. Lavery et al. [15] reported that lactating sows in their first parity are more sensitive to the loss of backfat than multiparous sows. Adequate amount of adipose tissue at the first service in gilts was shown to increase piglets born alive and total litter size in three subsequent parities [16]. It has been postulated, however, excessive body fat reserve stimulates reproductive failure, such as farrowing difficulties, stillborn piglets [14], higher culling rate, particularly because of locomotion difficulties [8]. However, these reports are not in agreement with the result of this study. In recent references such as Lavery et al. [15] study, a large range of gilt age and gilt body weight and backfat to find the most appropriate index of mating time, and their study did not show a reliable result for the best mating time that is supported by the result of the current study. However, they suggested that a minimum weight and backfat have to be achieved to ensure gilts puberty.

The tendency for lower FI in older $(\geq 240)$ or heavier $(\geq 150)$ gilts in the first parity may be associated with higher plasma leptin. In agreement with the result of this study, the definite negative influence of body weight and backfat of sows on feed intake during lactation has been confirmed [15]. A logical consequence of the tendency for higher feed intake in lighter gilts is a lower backfat thickness and lower plasma leptin levels [17], which directly affects the appetite, and presumably lower feed intake. Leptin mostly secrete from adipose tissue that has been detected as an effective hormone on reproduction action and FI regulation in sows. Here we report that older and heavier gilts had a higher backfat thickness, consequently greater adipose tissue. Earlier reports in pigs found the connection between leptin concentration and feed intake [18]. This suggests that reduction of feed intake in sows can be affected by the increase of leptin concentration. In our study, although the leptin was affected in WT sows at the second parity, some decrease in feed intake was expected in heavier sows but no significant difference was detected between the groups.

There are conflicting results in the studies regarding the mating age and litter performance. The result of the present study did not show any significant differences among the groups. In contrast, the influence of the percentage of repeat breeding has been investigated and gilts with a lower age at first mating had a higher percentage of repeat breeding [19]. On the other hand, Calderon Diaz et al. [20] reported that the age of gilts did not affect puberty time and also there is not any correlations between age at puberty and BW, and performance of gilts. This is in agreement with the result of this study that shows a short range of age around $230 \mathrm{~d}$ and weight of $145 \mathrm{~kg}$ in gilts at insemination had no effects on longevity and litter size.

Blood metabolites may account as indicators of the metabolic status of gilts to help the best gilts selection. In the current study, greater plasma leptin concentration at insemination time was associated with the age of gilts. This difference in plasma leptin was consistently apparent at farrowing and weaning times, supporting similar results in the study of Valros et al. [21], where a higher saliva leptin was detected in heavy sows. Clearly, in swine, the correlation between circulating leptin in plasma and adipose tissue mass have been recognized as a potent regulator of reproductive 
neuroendocrine axis in gilts [18]. Negative energy balance rapidly decreases the concentration of adipose tissue and plasma leptin. Therefore, the greater adipose tissue increases circulating plasma leptin due to a long-period of positive energy balance, as it has been shown in our study that leptin level increased in sows with higher body weight. In the current experiment, gilts with mating at a younger age ( $<220 \mathrm{~d}$ of age) had lower plasma leptin at breeding, farrowing and weaning time compared with those mated at an older age similar to results reported by Quesnel et al. [17]. It does not seem that the main function of leptin is to prevent obesity, however, it can be a physiological response to adapt the sows to starvation. One item to consider in our study was that we measured plasma Leptin and IGF-1 only for three parities to recognize the second parity syndrome in affected sows. The role of plasma leptin and IGF-1 in controlling the rate of growth and onset of puberty have been recognized.

\section{Conclusion}

In conclusion, body weight and plasma leptin of sows were influenced by age and weight of gilts at the first mating, but it is unlikely that longevity and litter performance are affected by age or weight of gilts at first mating. Therefore, a lower mating age (220 d) and weight $(140 \mathrm{~kg})$ seem to be more efficient.

\section{Competing interests}

No potential conflict of interest relevant to this article was reported.

\section{Funding sources}

Not applicable.

\section{Acknowledgements}

This work was carried out with the support of Cooperative Research Program for Agriculture Science and Technology Development (Project No. PJ00941003), Rural Development Administration, Korea.

\section{Availability of data and material}

Upon reasonable request, the datasets of this study can be available from the corresponding author.

\section{Authors' contributions}

Conceptualization: Chae BJ, Kim YH.

Data curation: Lee JH, Lee SH.

Formal analysis: Kim MJ.

Methodology: Kim KY, Choi YH.

Software: Hosseindoust A.

Validation: Lee JH, Lee SH.
Investigation: Kim KY, Lee SH.

Writing - original draft: Lee JH.

Writing - review \& editing: Hosseindoust A.

\section{Ethics approval and consent to participate}

The project underwent proper ethical standards and the experiments (KW-170519-1) were approved by the Institutional Animal Care and Use Committee of Kangwon National University, Chuncheon, Korea.

\section{ORCID}

SuHyup Lee https://orcid.org/0000-0001-8996-3740

Abdolreza Hosseindoust https://orcid.org/0000-0001-9191-0613

YoHan Choi https://orcid.org/0000-0003-4710-4731

MinJu Kim https://orcid.org/0000-0001-6950-0458

KwangYeol Kim https://orcid.org/0000-0002-3723-2978

JunHyung Lee https://orcid.org/0000-0002-7937-7817

YoungHwa Kim https://orcid.org/0000-0002-9850-8894

ByungJo Chae https://orcid.org/0000-0002-8570-698X

\section{References}

1. Engblom L, Lundeheim N, Dalin AM, Andersson K. Sow removal in Swedish commercial herds. Livest Sci. 2007;106:7686.

2. Quinn AJ, Green LE, Lawlor PG, Boyle LA. The effect of feeding a diet formulated for developing gilts between $70 \mathrm{~kg}$ and $-140 \mathrm{~kg}$ on lameness indicators and carcass traits. Livest Sci. 2015;174:87-95.

3. Yang KY, Jeon JH, Kwon KS, Choi HC, Kim JB, Lee JY. Effect of different parities on reproductive performance, birth intervals, and tail behavior in sows. J Anim Sci Technol. 2019;61:147-53.

4. Patterson JL, Beltranena E, Foxcroft GR. The effect of gilt age at first estrus and breeding on third estrus on sow body weight changes and long-term reproductive performance. J Anim Sci. 2010;88:2500-2513.

5. Casey T, Harlow K, Ferreira CR, Sobreira TJP, Schinckel A, Stewart K. The potential of identifying replacement gilts by screening for lipid biomarkers in reproductive tract swabs taken at weaning.J Appl Anim Res. 2018;46:667-76.

6. Koketsu Y, Takahashi H, Akachi K. Longevity, lifetime pig production and productivity, and age at first conception in a cohort of gilts observed over six years on commercial farms. J Vet Med Sci. 1999;61:1001-5.

7. Amer PR, Ludemann CI, Hermesch S. Economic weights for maternal traits of sows, including sow longevity 1.J Anim Sci. 2014;92:5345-57. 
8. Malopolska MM, Tuz R, Lambert BD, Nowicki J, Schwarz T. The replacement gilt: current strategies for improvement of the breeding herd.J Swine Health Prod. 2018;26:208-14.

9. Evans ACO, O'Doherty JV. Endocrine changes and management factors affecting puberty in gilts. Livest Prod Sci. 2001;68:1-12.

10. Amdi C, Giblin L, Ryan T, Stickland NC, Lawlor PG. Maternal backfat depth in gestating sows has a greater influence on offspring growth and carcass lean yield than maternal feed allocation during gestation. Animal. 2014;8:236-44.

11. National Research Council [NRC]. Nutrient requirements of swine. 11th ed. Washington, DC: National Academy Press; 2012.p.420.

12. Faccin JEG, Laskoski F, Lesskiu PE, Paschoal AFL, Mallmann AL, Bernardi ML, et al. Reproductive performance, retention rate, and age at the third parity according to growth rate and age at first mating in the gilts with a modern genotype. Acta Sci vet. 2017;45:1452.

13. Nielsen SE, Kristensen AR, Moustsen VA. Litter size of Danish crossbred sows increased without changes in sow body dimensions over a thirteen year period. Livest Sci. 2018;209:736.

14. Williams NH, Patterson J, Foxcroft G. 2005. Non-negotiables of gilt development. Adv Pork Prod. 16:281-289.

15. Lavery A, Lawlor PG, Magowan E, Miller HM, O'Driscoll K, Berry DP. An association analysis of sow parity, live-weight and back-fat depth as indicators of sow productivity. Animal.
2019;13:622-30.

16. Tummaruk P, Tantasuparuk W, Techakumphu M, Kunavongkrit A. Age, body weight and backfat thickness at first observed oestrus in crossbred Landrace $\times$ Yorkshire gilts, seasonal variations and their influence on subsequence reproductive performance. Anim Reprod Sci. 2007;99:167-81.

17. Quesnel H, Mejia-Guadarrama CA, Dourmad JY, Farmer C, Prunier A. Dietary protein restriction during lactation in primiparous sows with different live weights at farrowing: I. consequences on sow metabolic status and litter growth. Reprod Nutr Dev. 2005;45:39-56.

18. Barb CR, Hausman GJ, Czaja K. Leptin: a metabolic signal affecting central regulation of reproduction in the pig. Domest Anim Endocrinol. 2005;29:186-92.

19. Tummaruk P, Lundeheim N, Einarsson S, Dalin AM. Effect of birth litter size, birth parity number, growth rate, backfat thickness and age at first mating of gilts on their reproductive performance as sows. Anim Reprod Sci. 2001;66:225-37.

20. Calderon Diaz JA, Vallet JL, Prince TJ, Phillips CE, DeDecker AE, et al. Optimal dietary energy and amino acids for gilt development: growth, body composition, feed intake, and carcass composition traits. J Anim Sci. 2015;93:1187-99.

21. Valros A, Pedersen LJ, Poytakangas M, Jensen MB. Evaluating measures of exploratory behaviour in sows around farrowing and during lactation: a pilot study. Appl Anim Behav Sci. 2017;194:1-6. 